\title{
Research Notes
}

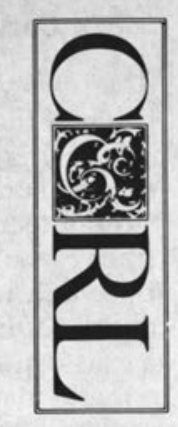

\section{A Conjoint Analysis of Reference Services in Academic Libraries}

\author{
Gregory A. Crawford
}

Conjoint analysis has been used by market researchers for the development of many products and services. This article displays the potential of conjoint analysis for evaluating reference services in academic libraries. Six dimensions of reference service are included in the analyses: definitiveness of answer, in line wait times, service time, number of items given to patron, hours of service, and cost of service. Of greatest importance to users are cost of the service and the hours during which reference is available. Most users prefer that all reference services be free and that reference help be available at all times the library is open.

ne of the primary goals of marketing is to provide products or services that will appeal to the preferences of consumers. Preferences, however, may vary among individuals and the final product or service offered must involve trade-offs of specific levels of the attributes desired by consumers. As a result, marketing strives to develop products or services that match the preferences of the consumers in such a way as to make them as appealing as possible to the largest number of consumers.

Similarly, one of the primary goals of libraries is to provide services that meet the information needs and desires of their patrons. In a recent $R Q$ editorial addressing the promotion of libraries, Susan S. DiMattia says, "Our promotional efforts tell about how libraries make information affordable, accessible, and available. We keep telling the public how wonderful we are, but we don't ask the public what they need. We don't seem to listen too much, we're so busy talking." 1

Because patrons will vary in their preferences for specific library services, a method to assist in developing services to meet the desires of patrons could prove to be a great benefit to library administrators when used in conjunction with statements of the mission and

Gregory A. Crawford is Head of Public Services at the Pennsylvania State University-Harrisburg, Harrisburg, Pennsylvania. This research was done while the author was a student in the Ph.D. program in Communication, Information and Library Studies at Rutgers University. The author would like to express his appreciation to Paul Kantor (Rutgers University) for his valuable insights and assistance in this project and for his helpful comments on the final draft of this paper. Special thanks go to Valerie Manusov (Rutgers University), Robert Pruznick (Warren County Community College), and Lori Toedter (Moravian College) for permitting their students to participate in this research. 
goals of the individual library. Conjoint analysis is one possible method of assessing such preferences.

As a technique, conjoint analysis can trace it roots to an article by $R$. Duncan Luce and John W. Tukey in $1964 .^{2}$ Luce, a pioneer in decision theory, and Tukey, a leader in statistical analysis, developed a mathematical way to transform user's rankings of arbitrary combinations of attributes into a scale of measurement, usually called utility. Thus, the importance of different features can be reexpressed on additive interval scales whose units are equivalent and whose zero point is arbitrary. The result is a model of the user's preferences when all the attributes are considered together. Such a model has ready application in many fields of the behavioral sciences. Marketing researchers have developed the technique of conjoint analysis, based upon the work of Luce and Tukey, and have used it heavily for the planning and development of new products.

In library and information science research, there have been only a few attempts to use conjoint analysis in the study of library services.

Within marketing research, conjoint analysis is based in large part on the work of Paul E. Green. Over the last two decades, Green and his coauthors have published numerous articles on the use of conjoint analysis in consumer research. ${ }^{3}$ In 1971 Green and Vithala R. Rao introduced conjoint measurement as one method for quantifying judgmental data that could be useful for marketing researchers. ${ }^{4}$ In a 1972 empirical study Green, Frank J. Carmone, and Yoram Wind concluded that additive conjoint models provided good descriptions of data from their study even when compared to descriptions produced by more complex models. ${ }^{5}$

By the late 1970 s, conjoint analysis had spawned a growing body of theoretical literature, as reviewed and later updated by Green and Srinivasan. ${ }^{6}$ Com- mercial uses of conjoint analysis have been reviewed by Philippe Cattin and Dick R. Wittink. ${ }^{7}$ Cattin and Wittink identified 698 uses of the methodology by marketing research firms during the ten years following the first commercial project involving conjoint analysis in 1971 . In their follow-up article, Wittink and Cattin documented at least 1,062 projects using conjoint analysis over the five-year period from 1981 to 1985 , and estimated that there may in actuality have been approximately 2,000 such projects.

As an analytical technique, conjoint analysis strives to decompose or separate a set of predetermined "stimuli," which are attributes of some item (e.g., a commercial product or service) so that the utility of each level of stimulus or attribute can be inferred from the overall evaluations given by subjects. ${ }^{8}$ The procedures used in particular conjoint analyses vary, but they all maintain a factorial design in which all levels of each stimulus or attribute can be compared to all levels of all other stimuli or attributes.

Richard M. Johnson, cited by many later articles, used a variation of conjoint measurement to study the value systems of individual consumers. ${ }^{9} \mathrm{He}$ called his method trade-offanalysis. The basis of his argument rested on the assumption that the choice behavior of individual consumers is governed by trade-offs that "may be revealed by choices among product concepts having characteristics which are varied in systematic ways." 10 The result of such analysis is a model of preferences for product or service characteristics stated in the form of utilities for each attribute. It is then possible to determine the optimal configuration of product characteristics by selecting the highest rated attributes.

In library and information science research, there have been only a few attempts to use conjoint analysis in the study of library services. Michael Halperin and Maureen Strazdon examined preferences for reference services using conjoint analysis." They used eight factors: completeness and accuracy of answer (4 levels), database serv- 
ice (4 levels), interlibrary loans ( 2 levels), time needed to answer question ( $2 \mathrm{lev}-$ els), attitude of librarians (3 levels), hours of reference service (2 levels), knowledge of librarians (2 levels), and wait for service (2 levels). The authors concluded: "Conjoint analysis is a technique that allows us to quantify some of the seemingly intractable qualitative aspects of library service. In doing so it represents a new and potentially fruitful method of relating library services to user requirements."12

In another article, Halperin discussed the potential of conjoint analysis to help inform library administrators of user preferences for information services. ${ }^{13}$ Although they did not actually perform a study using conjoint analysis, Kenneth D. Ramsing and John R. Wish illustrated the use of the technique to determine the service preferences of library users, with their main example being online searching. ${ }^{14}$ Thus, Halperin, Strazdon, and Ramsing and Wish have shown that conjoint analysis has potential applicability to library and information science. This potential has yet to be tapped.

In brief, conjoint analysis could be used to determine the attributes of a library or information service that are most important to library patrons. Utilities or "part-worth" weights can be derived for all levels of each attribute from reports by respondents completing the conjoint instrument. Attributes could then be segmented by different user groups in order to meet the desires of those groups as expressed by their preferences, for example, by gender, age, institutional affiliation, or amount of library use.

Since the derived part-worths or utility scores are additive, it should be possible to determine the level of patron satisfaction with current library and information services by simply adding the utility scores of those levels of attributes that the services currently possess. This number could then be compared to the total of utility scores of alternative schemes of services. A library with a larger total could be said to meet better the preferences of users while a library with a lower total could be said to be deficient in some area or areas. The area or areas of deficiency could then be ameliorated or eliminated by striving to provide the service attributes preferred by patrons. Conjoint analysis, therefore, could provide a method for predicting patron satisfaction if current services are changed in specific ways.

The major caveat about conjoint analysis is that it focuses on elicited consumer preferences among hypothetical choices. Such preferences may or may not translate into behavior. For example, preference for less expensive database searching may not necessarily mean that, if the library lowered fees for searching, more patrons would use the service. In addition, altering services to meet patron desires may necessitate restructuring of funding, reassignment of staff, changing library hours, etc. These may negate the projected increases in utility to patrons. Finally, since patrons differ on sociodemographic and psychographic variables, it may be difficult to change library or information services to meet the preferences of all patrons. Nonetheless, conjoint analytic techniques may be very beneficial in the marketing of library services to specific segments of the population or in establishing new services aimed at these specific user segments. It can help in decision making because it can provide data on patron preferences that were not obvious before.

\section{METHODOLOGY}

This research applied conjoint analysis to the user preferences for reference service in the academic library, similar to the research of Halperin and Strazdon. Six attributes of reference services were selected for this study: (1) Definitiveness refers to the likelihood that an answer to a question can be found in materials given to a patron by a librarian; (2) Hours of service describes the times during which a librarian is available to assist patrons; (3) Cost of service means the actual monetary charges that will have to be paid for interlibrary loan (ILL) and the searching of online databases $(\mathrm{db}$ searching); (4) In line wait time refers to the 
length of time patrons must stand in line or wait for a librarian to assist them; (5) Number of items indicates how many physical items (books, magazines, maps, etc.) a librarian helps a patron find or gives to a patron in order to answer his or her question(s); and (6) Service time refers to the length of time it takes a librarian to answer a question or assist a patron. The levels of each attribute are given in table 1.

This study includes four attributes similar to those of Halperin and Strazdon, but utilizes a different number of levels for each: "Hours of service," "In line wait time" ("Wait for service" in Halperin and Strazdon), "Definitiveness" (called "Completeness of answer"), and "Service time" ("Time needed to answer"). The "Cost of service" attribute incorporates two of theirs: database searching and interlibrary loans. The rationale for this combined attribute is that database searching

\section{TABLE 1}

REFERENCE SERVICES:

\section{ATTRIBUTES AND THEIR LEVELS}

1. Definitiveness

(1) definite answer

(2) possible answer

2. Hours of Service

(1) any time library open

(2) specified times only

(3) by appointment only

3. Cost of Service

(1) all services free

(2) less than $\$ 5$ for interlibrary loan and database searching

(3) over $\$ 5$ for interlibrary loan and database searching

4. In Line Wait Time

(1) less than 5 minutes

(2) 5 to 15 minutes

(3) more than 15 minutes

5. Number of Items

(1) 1 item

(2) 2 to 5 items

(3) 6 or more items

6. Service Time

(1) less than 5 minutes

(2) 5 to 15 minutes

(3) more than 15 minutes and interlibrary loan are the two services provided by the reference or public services department with which charges are often associated. Two attributes in the Halperin and Strazdon study, attitude of librarians and knowledge of librarians, are not included in the present study to avoid problems in patron judgments of librarian knowledge and attitude. One new attribute is included: number of items. The attributes included in the present study can all be, at least to some extent, quantified or measured within the library; librarian knowledge and attitude cannot be so easily quantified.

To test for differences among students in academic institutions that vary in size and type, undergraduate students from three colleges and universities were surveyed: Rutgers University, Moravian College, and Warren County (New Jersey) Community College. In addition, Rutgers M.L.S. students taking a research methods class completed the conjoint instrument to provide comparative data for graduate students. All respondents were asked the following demographic questions: age, gender, major field of study, and the number of times they visit the library each week. A total of 100 usable instruments were collected. (See table 2 for a breakdown by institution.) Four instruments were incomplete and, therefore, unusable. Three of these were from Warren County Community College and one was from Moravian College. All of the unusable instruments contained incomplete data for the trade-off matrices involving the cost of service attribute.

Data analyses included $t$-tests for each level of every attribute to test for differ-

\section{TABLE 2}

BREAKDOWN OF SUBJECTS BY INSTITUTION

\begin{tabular}{lr}
\hline Moravian College & 32 \\
Rutgers (undergraduates) & 40 \\
Rutgers (M.L.S.) & 15 \\
Warren County Community College & 13 \\
Total & 100 \\
\hline
\end{tabular}


ences between the genders and one-way analysis of variance tests for all levels of each attribute to test for differences between respondents stratified by age, institution, and frequency of library use. The .05 level of significance was used for all inferential statistical tests. Due to the total number of $t$-tests and ANOVAs included in the analysis, chance alone may account for approximately three significant results.

Respondents included 77 women and 23 men. Ages ranged from 18 to 46 (two subjects did not give their ages), with 66 percent of the total respondents being 18 to 21 years of age. Ages were grouped into the following spans: 18-20, 21-30, $31-40$, and 41 and above. For the institutional ANOVA test, the groups are Warren County (New Jersey) Community College, Moravian College, Rutgers University undergraduates, and Rutgers University M.L.S. students.

The respondents used the library an average of 2.3 times per week (std. dev. $1.64)$, with a range of zero to ten times per week. Over half of the respondents (55) said that they used the library once or twice a week. Eight said that they never used the library or used it less than once per week. Thirty-six used the library three or more times a week. One respondent did not answer this question. For an additional ANOVA test of preferences, the respondents were classified into three categories of library use: (1) less than one use per week $(n=8),(2)$ one to two uses per week $(n=55)$, and (3) three or more uses per week $(n=36)$.

Academic majors of the undergraduate respondents represented twentynine different majors or combinations of majors. No discernible pattern of majors was observed. All the Rutgers undergraduate respondents were enrolled in a communications class and were majoring in either communication or a closely related field. The respondents from Moravian College and Warren County Community College were taking an introductory psychology class. Moravian respondents represented fourteen different majors while the community college students reported six majors.
The resulting sample of respondents constitutes a nonprobability, convenience sample, drawn from classes whose instructors agreed to participate. The lack of random selection of subjects may decrease the external validity of the results of the study. The total sample, however, does consist of a wide variety of students as evidenced by the large number of majors, the differences in ages, the differences in institution types, and the differences in library usage.

In the "full profile" approach, subjects are asked to rank descriptions of all possible combinations of levels of attributes of services or products.

Because of the length of time it takes to complete, the "full profile" conjoint approach was not used. In the full profile approach, subjects are asked to rank descriptions of all possible combinations of levels of attributes of services or products. One method of reducing the number of descriptions to be ranked is the use of orthogonal arrays of attributes in which combinations of factors are selected in such a way as to balance the contribution of each factor. ${ }^{15}$ Because of the ease of instrument construction and administration, the two-factor method was chosen for this study.

The reference service preference data were collected by Johnson's two-factorat-a-time method. The six attributes being examined yield fifteen different trade-off matrices, each of which was printed on a half sheet of paper (8.5 inches by 5.5 inches). See appendix A for a sample trade-off matrix from the conjoint instrument.

Respondents were given a data-collection instrument consisting of a cover sheet with directions, the fifteen tradeoff matrices assembled randomly for each instrument, and a final sheet asking the demographic questions. Respondents were directed to rank their preferences for the combinations of the levels of two attributes represented in each trade-off matrix on either a one-to-nine or a one-to-six 
TABLE 3

SUMMARY UTILITIES BY INSTITUTION

\begin{tabular}{|c|c|c|c|c|c|c|c|c|c|c|c|c|c|c|c|c|c|}
\hline \multirow{2}{*}{$\begin{array}{l}\text { Attribute } \\
\text { Level: }\end{array}$} & \multicolumn{2}{|c|}{1} & \multicolumn{3}{|c|}{2} & \multicolumn{3}{|c|}{3} & \multicolumn{3}{|c|}{4} & \multicolumn{3}{|c|}{5} & \multicolumn{3}{|c|}{6} \\
\hline & 1 & 2 & 1 & 2 & 3 & 1 & 2 & 3 & 1 & 2 & 3 & 1 & 2 & 3 & 1 & 2 & 3 \\
\hline \multicolumn{18}{|c|}{ Moravian College } \\
\hline Mean & .51 & .04 & .59 & .35 & .07 & .91 & .52 & .07 & .54 & .31 & .03 & .19 & .26 & .31 & .46 & .28 & .08 \\
\hline St. dev. & .36 & .21 & .37 & .29 & .22 & .36 & .24 & .27 & .34 & .16 & .09 & .23 & .18 & .37 & .27 & .18 & .17 \\
\hline Minimum & 0 & 0 & 0 & 0 & 0 & 0 & 0 & 0 & 0 & 0 & 0 & 0 & 0 & 0 & 0 & 0 & 0 \\
\hline Maximum & 1.65 & 1.18 & 1.22 & 1.33 & 1.04 & 1.56 & 1.32 & 1.34 & 1.17 & .70 & .40 & .70 & .65 & 1.12 & .88 & .61 & .61 \\
\hline \multicolumn{18}{|c|}{ Rutgers University-Undergraduate } \\
\hline Mean & .79 & .03 & .67 & .34 & .05 & .93 & .47 & .06 & .64 & .36 & .05 & .14 & .27 & .28 & .48 & .24 & .05 \\
\hline St. dev. & 1.38 & .10 & .35 & .25 & .16 & .39 & .24 & .21 & .29 & .17 & .18 & .23 & .21 & .27 & .25 & .14 & .14 \\
\hline Minimum & 0 & 0 & 0 & 0 & 0 & 0 & 0 & 0 & 0 & 0 & 0 & 0 & 0 & 0 & 0 & 0 & 0 \\
\hline Maximum & 7.99 & .55 & 1.27 & .78 & .93 & 1.49 & 1.11 & 1.24 & 1.08 & .62 & .82 & .73 & .73 & .91 & 1.05 & .59 & .54 \\
\hline \multicolumn{18}{|c|}{ Rutgers University-M.L.S. Students } \\
\hline Mean & .53 & 0 & .77 & .40 & 0 & .99 & .51 & 0 & .77 & .41 & .01 & .15 & .40 & .30 & .49 & .29 & .01 \\
\hline St. dev. & .21 & 0 & .25 & .20 & 0 & .25 & .19 & 0 & .24 & .25 & .04 & .24 & .24 & .33 & .28 & .22 & .03 \\
\hline Minimum & .04 & 0 & .28 & .05 & 0 & .46 & .22 & 0 & .17 & 0 & 0 & 0 & .03 & 0 & 0 & 0 & 0 \\
\hline Maximum & .85 & 0 & 1.09 & .69 & 0 & 1.26 & .98 & 0 & 1.07 & 1.07 & .15 & .69 & .85 & .91 & .92 & .69 & .08 \\
\hline \multicolumn{18}{|c|}{ Warren County (NJ) Community College } \\
\hline Mean & .31 & .03 & .74 & .30 & .03 & .77 & .42 & .04 & .51 & .37 & .02 & .25 & .22 & .18 & .46 & .30 & .06 \\
\hline St. dev. & .31 & .08 & .42 & .21 & .11 & .46 & .27 & .15 & .40 & .22 & .05 & .28 & .17 & .29 & .34 & .23 & .17 \\
\hline Minimum & 0 & 0 & 0 & .01 & 0 & 0 & 0 & 0 & 0 & 0 & 0 & 0 & 0 & 0 & 0 & .03 & 0 \\
\hline Maximum & .82 & .28 & 1.35 & .66 & .38 & 1.34 & .71 & .55 & 1.34 & .66 & .14 & .75 & .61 & .88 & .91 & .86 & .57 \\
\hline \multicolumn{18}{|l|}{ Total Group } \\
\hline Mean & .60 & .03 & .67 & .35 & 05 & .91 & .49 & .05 & .61 & .35 & .04 & .17 & .28 & .28 & .47 & .27 & .06 \\
\hline St. dev. & .92 & .14 & .35 & .25 & .16 & .37 & .24 & .21 & .32 & .19 & .13 & .24 & .21 & .31 & .27 & .18 & .15 \\
\hline Minimum & 0 & 0 & 0 & 0 & 0 & 0 & 0 & 0 & 0 & 0 & 0 & 0 & 0 & 0 & 0 & 0 & 0 \\
\hline Maximum & 7.99 & 1.18 & 1.35 & 1.33 & 1.04 & 1.56 & 1.32 & 1.34 & 1.34 & .80 & .82 & .75 & .85 & 1.12 & 1.05 & .86 & .61 \\
\hline
\end{tabular}




\section{TABLE 4}

RANGES AND RELATIVE IMPORTANCE OF EACH ATTRIBUTE

\begin{tabular}{|c|c|c|c|c|}
\hline Attribute & $\begin{array}{l}\text { Utility } \\
\text { Scores }\end{array}$ & Range & $\begin{array}{c}\% \text { of Total } \\
\text { Range }\end{array}$ & Rank \\
\hline Cost of service & & .86 & 27 & 1 \\
\hline All services free & .91 & & & \\
\hline Less than $\$ 5$ & .49 & & & \\
\hline$\$ 5$ and over & .05 & 4 & & \\
\hline Hours of service & & .62 & 20 & 2 \\
\hline Any time library is open & .67 & & & \\
\hline Specified times only & .35 & & & \\
\hline By appointment only & .05 & & & \\
\hline In line wait time & & .57 & 18 & 3.5 \\
\hline Less than 5 minutes & .61 & & & \\
\hline 5 to 15 minutes & .35 & & & \\
\hline More than 15 minutes & .04 & & & \\
\hline Definitiveness & & .57 & 18 & 3.5 \\
\hline Definite answer & .60 & & & \\
\hline Possible answer & .03 & & & \\
\hline Service time & & .41 & 13 & 5 \\
\hline Less than 5 minutes & .47 & & & \\
\hline 5 to 15 minutes & .27 & & & \\
\hline More than 15 minutes & .06 & & & \\
\hline Number of items & & .11 & 4 & 6 \\
\hline 1 item & .17 & & & 2 \\
\hline $2-5$ items & .28 & & & \\
\hline 6 or more items & .28 & & & \\
\hline Total Range & & 3.14 & 100 & \\
\hline
\end{tabular}

scale, matching the number of pairs to be compared. Completion of the instrument took approximately twenty minutes.

Utility calculations were performed for each respondent using the trade-off program, part of the PC-MDS package of programs written by Scott Smith of Brigham Young University. ${ }^{16}$ Other analyses were completed using SPSS$\mathrm{PC}+$ Studentware software.

\section{RESULTS}

Table 3 presents summary utility data for each of the three institutions involved in this research, with Rutgers University represented twice, once for undergraduates and once for M.L.S. students. The mean, standard deviation, minimum, and maximum of the students' utility scores are given for all lev- els of each attribute. In addition, the means, standard deviations, minimum, and maximum utility scores are given for the entire sample.

The ranges and relative importance for each attribute level are given in table 4. This table reveals that the total range of scores is 3.14. The importance of each attribute is given by the percentage that it contributes to this total range.

The cost of service is the single most important variable in the student perception of academic reference services, accounting for 27 percent of the total range of scores. Most patrons prefer that all services be free, including interlibrary loan and database searching. For comparison, in the Halperin and Strazdon study, cost of database service ranked second in importance and cost of 
TABLE 5

SUMMARY OF SIGNIFICANT DIFFERENCES IN UTILITY SCORES

\begin{tabular}{llcccc}
\hline Group & \multicolumn{1}{c}{ Attribute } & \multicolumn{1}{c}{ Level } & $t$ & $\mathrm{p}$ & $\mathrm{d} / \mathrm{f}$ \\
\hline & & T-Tests & & & \\
1. Gender & Definitiveness & 2 (possible answer) & 2.36 & .02 & 98 \\
2. Gender & Number of items & 3 (6 or more items) & 2.57 & .01 & 98
\end{tabular}

Analysis of Variance Tests

\begin{tabular}{llllll} 
3. Age & Service time & 1 (less than 5 minutes) & 2.71 & .05 & $3 / 94$ \\
4. Age & In line wait time & 1 (less than 5 minutes) & 3.75 & .01 & $3 / 94$ \\
5. Library Use & Definitiveness & 2 (possible answer) & 3.51 & .03 & $2 / 96$ \\
6. Institution & Variable = library use & & 3.89 & .01 & $3 / 95$ \\
\hline
\end{tabular}

interlibrary loan ranked fifth. Together, these two factors represent 27.5 percent of the total range of scores yielded by their study. The second most important factor in the current research is the hours during which reference service is available ( 20 percent of total range), with reference service available at any time the library is open the preferred mode. This factor ranked fourth in Halperin and Strazdon, representing 10 percent of their total range. Tied for third place in the current study are definitiveness of the answer and in line wait time (18 percent each). Students overwhelmingly prefer a definite answer to a possible answer and also prefer to wait less than five minutes for service. In comparison, Halperin and Strazdon report that "Completeness of answer" ranked first in their study ( 34.5 percent of total range) and "Wait for service" ranked eighth ( 3.6 percent). In fifth place, service time accounts for 13 percent of the range, with most patrons preferring to have a librarian help them for less than five minutes. Halperin and Strazdon's factor, "time needed for answer," ranked seventh. Number of items given to the patron ranks sixth and provides little influence on the perception of reference service, accounting for only 4 percent of the range. No similar factor was included in Halperin and Strazdon.

Assuming that the utility scores are additive, the highest possible mean score for all attributes taken at one time is 3.54 . The mean high utility score for each individual institution is as follows: 3.32 for Moravian College, 3.79 for Rutgers undergraduates, 3.95 for Rutgers M.L.S. students, and 3.29 for Warren County Community College. Since these scores are known, it would be possible to examine the reference services provided by the library in each of the studied institutions in order to compare their current level of service to the level of service preferred by patrons as indicated in the derived utility scores.

In addition, the utility scores can provide an indication of how satisfaction may change if an attribute of the service is changed. For example, if a library routinely charges a fee less than $\$ 5$ for interlibrary loan or database searching, it can potentially increase patron satisfaction by .42 if these services could be provided free. On the other hand, if it became necessary for a library to charge for such services, overall satisfaction levels might be maintained if other attributes are changed so that their utility scores compensate for the potential reduction in satisfaction associated with costs.

$T$-tests were run on all levels of each attribute to determine if any derived utility scores were significantly different between the genders. Analysis of variance (ANOVA) tests were performed on the utility scores to assess differences of individual institutions, age groups of respondents, and library use groupings. $T$-tests and ANOVAs were also run on the 
library use variable to determine differences by gender and by group of respondents. A summary of the statistically significant results is given in table 5 .

Men indicated a small but significantly higher preference for possible answers (level 2 of the attribute "Definitiveness") $(t=2.36, p=.02, d f=98)$. The mean utility scores for both men (.09) and women (.01), however, were negligible. Both genders overwhelmingly preferred a definite answer (level 1 of the attribute "Definitiveness"), with men giving it a utility score of $\mathbf{0 . 6 2}$ and women $\mathbf{0 . 5 9}$.

The only other significant difference revealed by the gender-based $t$-tests showed that women report a higher mean utility score on level 3, "six or more items," of the attribute Number of items $(t=2.57, p=0.01, d f=98)$. The mean utility score on this attribute level for women was 0.32 and for men 0.14 . In general, the utility scores show that women preferred six or more items $(0.59)$ to either one item $(0.16)$ or two to five items (0.29). Men, in contrast, had higher utility scores on both one item $(0.23)$ and two to five items $(0.25)$ than on six or more items $(0.14)$.

\section{Frequent users of the library may} be more savvy in obtaining the information they need and may be more aware of the variety of sources in which to find their answers.

The analysis of variance tests showed no significant differences between the respondents grouped by institution on any of the levels of the attributes. There is, however, a significant difference in library use between the groups $(F=3.89$, $p=.01, d f=3 / 95)$. Post hoc Scheffe tests reveal that this result is due only to the difference between the use of the library by the Rutgers undergraduates (mean $=1.8$ ) and the Rutgers M.L.S. students (mean = 3.43). No other differences between the groups are statistically significant.

Analysis of variance tests by age categories reveal significant differences on two levels of attributes: level 1 of "Serv- ice time" and level 1 of "In line wait time." Level 1 of the attribute "Service time" indicates that the respondents preferred reference service at any time the library is open. ANOVA tests reveal a significant difference between the four age categories of this level $(F=2.71, p=$ $.05, d f=3 / 94)$. Post hoc Scheffe tests, however, fail to reveal statistically significant differences among any two separate groups.

ANOVA tests result in a significant difference between the four age groupings on level 1 of the "In line wait time" attribute, i.e., a wait of less than five minutes $(F=3.75, p=.01, d f=3 / 94)$. Post hoc Scheffe tests show a significant difference in the utility scores of those aged 31 to 40 (mean $=.83$ ) and those aged 20 and under (mean $=.52)$.

ANOVA tests were also run on the utility scores of each level of all attributes with respondents grouped by amount of library use. Significant results were obtained only on level 2 ("possible answer") of the attribute "Definitiveness" $(F=3.57, p=.03, d f=2 / 94)$. Post hoc Scheffe tests indicated that the utility scores of those respondents using the library zero times per week (mean $=.15$ ) differed significantly from those using the library three or more times per week (mean $=.01)$.

\section{DISCUSSION}

The results of these analyses indicate that most college students agree on their preferences for academic reference services. As one might expect, they prefer a definite answer, reference service at any time the library is open, all services free, a less than five minute wait for service, two or more items, and less than five minutes of actually working with a librarian. Of these preferences, the most important factors, in ranked order, are the cost of the service, the hours of service, the length of wait for service, the definitiveness of the answer given, and the amount of service given. The number of items has little overall impact on preference.

Men and women express similar preferences on most levels of attributes as 
indicated by their utility scores. Only two statistically significant differences emerged in the analyses. First, while women and men both overwhelmingly desire a definite answer, men are more accepting of a possible answer than women. Second, women prefer to be given more items than men, giving a utility score of 0.32 for six or more items compared to men's score of 0.14 . Men prefer to be given one to five items.

Contrary to expectations, the institutional affiliation of respondents did not affect the utility scores. No significant differences in any levels of any attributes appeared in the analyses. A significant difference did emerge in the amount of library use with Rutgers M.L.S. students using the library significantly more than Rutgers undergraduates.

Analyse by age categories also failed to show many significant differences. The only significant differences discovered were between those aged 31 to 40 and those 20 and under. Older individuals indicated a significantly higher preference, as shown by their utility scores, for quick service, i.e., they wished to wait in line for no more than five minutes. This may be a reflection of their situation in life with more responsibilities. Most of the older students are employed full-time and are enrolled in school part-time. Thus, when they are at the library, they wish to have services readily available to them, and they do not wish to wait long for those services.

Finally, only one significant difference was found when the respondents were stratified by the amount of their library use. Those who used the library heavily (i.e., three or more times per week), gave a very low preference for a possible answer when compared to those who used the library very few times (i.e., less than once per week). Frequent users of the library may be more savvy in obtaining the information they need and may be more aware of the variety of sources in which to find their answers. Overall, the results of this study indicate a fairly stable pattern of preferences for reference services in the academic library.

\section{CONCLUSION}

Conjoint analysis provides a method for determining patron preference to guide librarians in structuring reference services in the academic library. While individual students will vary in their preferences for specific aspects of service, the means of the utility scores derived from the stated preferences of these individuals reveal which aspects of existing services should be emphasized or deemphasized. Similar research can be done to determine the preferences of other members of the academic community who may have different service preferences than undergraduates, especially faculty, administration, and graduate students.

Librarians should adopt and adapt techniques from other fields such as marketing in order to improve the effectiveness of libraries. This study shows that conjoint analysis can be useful and encourages us to search for other such tools.

\section{REFERENCES AND NOTES}

1. Susan S. DiMattia, "Dogs-or Stars?" RQ 31 (1992): 307-9.

2. R. Duncan Luce and John W. Tukey, "Simultaneous Conjoint Measurement: A New Type of Fundamental Measurement," Journal of Mathematical Psychology 1 (1964): 1-27.

3. Paul E. Green, "On the Design of Choice Experiments Involving Multifactor Alternatives," Journal of Consumer Research 1(1974): 61-68; Paul E. Green, "Hybrid Models for Conjoint Analysis: An Expository Review," Journal of Marketing Research 21 (1984): 155-69; Paul E. Green and Yoram Wind, "New Way to Measure Consumers' Judgments," Harvard Business Review 53 (July/Aug. 1974): 107-17; Paul E. Green and Abba M. Krieger, "Segmenting Markets with Conjoint Analysis," Journal of Marketing 55 (Oct. 1991): 20-31; Paul E. Green and V. Srinivasan, "Conjoint Analysis in Consumer Research: Issues and Outlook," Journal of Consumer Research 5 (1978): 103-23; and Paul E. Green and V. Srinivasan, "Conjoint 
Analysis in Marketing: New Developments with Implications for Research and Practice," Journal of Marketing 54 (Oct. 1990): 3-19.

4. Paul E. Green and Vithala R. Rao, "Conjoint Measurement for Quantifying Judgmental Data," Journal of Marketing Research 8 (1971): 355-63.

5. Paul E. Green, Frank J. Carmone, and Yoram Wind, "Subjective Evaluation Models and Conjoint Measurement," Behavioral Science 17 (1972): 288-99.

6. Green and Srinivasan, "Conjoint Analysis in Consumer Research" and Green and Srinivasan, "Conjoint Analysis in Marketing."

7. Philippe Cattin and Dick R. Wittink, "Commercial Use of Conjoint Analysis: A Survey," Journal of Marketing 46 (Summer 1982): 44-53; and Dick R. Wittink and Philippe Cattin, "Commercial Use of Conjoint Analysis: An Update," Journal of Marketing 53 (1989): 91-96.

8. Green, Carmone, and Wind, 1972; Paul E. Green and D. S. Tull, Research for Marketing Decisions, 4th ed. (Englewood Cliffs, N.J.: Prentice-Hall, 1978); and Green and Wind, "New Way to Measure Consumers' Judgements."

9. Richard M. Johnson, "Trade-off Analysis of Consumer Values," Journal of Marketing Research 11 (1974): 121-27.

10. Ibid., 121.

11. Michael Halperin and Maureen Strazdon, "Measuring Students' Preferences for Reference Service: A Conjoint Analysis," Library Quarterly 50 (1980): 208-24.

12. Ibid., 223.

13. Michael Halperin, "Determining User Preferences for Information Services," Drexel Library Quarterly 17 (Spring 1982): 88-98.

14. Kenneth D. Ramsing and John R. Wish, "What Do Library Users Want? A Conjoint Measurement Technique May Yield the Answer," Information Processing and Management 18 (1982): 237-42.

15. See Green, "On the Design of Choice Experiments."

16. Scott Smith, PC-MDS Multidimensional Statistics Package [Computer program] (Provo, Utah: Scott Smith, 1990).

\section{APPENDIX A \\ Sample Trade-off Matrices from Conjoint Instrument}

"Cost of Service" means the actual monetary charges that you will have to pay for interlibrary loan (ILL) and the searching of online databases (db searching). "In Line Wait Time" means how long you must stand in line or wait for a librarian to assist you.

Cost of Service

\begin{tabular}{|l|l|l|l|}
\hline & All services free & $\begin{array}{c}\text { Less than \$5 for ILL } \\
\text { and db searching }\end{array}$ & $\begin{array}{c}\text { \$5 and over for ILL } \\
\text { and db searching }\end{array}$ \\
\hline Less than 5 minutes & & & \\
\hline 5 to 15 minutes & & & \\
\hline $\begin{array}{c}\text { More than } 15 \\
\text { minutes }\end{array}$ & & & \\
\hline
\end{tabular}

